\title{
Using LCA-based Decomposition Analysis to Study the Multidimensional Contribution of Technological Innovation to Environmental Pressures
}

\author{
David Font Vivanco, René Kemp, Ester van der Voet, and Reinout Heijungs
}

\section{Keywords:}

industrial ecology

innovation

IPAT equation

life cycle assessment (LCA)

rebound effect

transportation and environment

EII

Supporting information is available on the JIE Web site

\section{I}

\begin{abstract}
Summary
This article presents a general framework for macroenvironmental assessment, combining life cycle assessment (LCA) with the IPAT equation, and explores its combination with decomposition analysis to assess the multidimensional contribution of technological innovation to environmental pressures. This approach is illustrated with a case study in which carbon dioxide $\left(\mathrm{CO}_{2}\right)$ and nitrogen oxides $\left(\mathrm{NO}_{x}\right)$ air emissions from diesel passenger cars in Europe during the period 1990-2005 are first decomposed using index decomposition analysis into technology, consumption activity, and population growth effects. By a second decomposition, the contribution of a specific innovation (diesel engine) is calculated on the basis of the technology and consumption activity effects, through a technological comparison with a relevant alternative and the calculation of the rebound effect, respectively. The empirical analysis for diesel passenger cars highlights the discrepancies between the micro (LCA) and macro (IPAT-LCA) analytical approaches. Thus, whereas diesel engines present a relatively less-pollutant environmental product profile than their gasoline counterparts, total $\mathrm{CO}_{2}$ and $\mathrm{NO}_{x}$ emissions would have increased partly as a consequence of their introduction, mainly driven by the increase in travel demand caused by the induced direct price rebound effect from fuel savings and fuel price differences. The counterintuitive result shows the need for such an analysis.
\end{abstract}

\section{Introduction}

It seems to be the general belief that technological innovation is going to be the key to many of the environmental challenges we currently face (Grübler 2003; Kemp 1994). However, though products are generally becoming lighter and more energy efficient, overall environmental impacts are increasing in almost all parts of the world. For instance, in Europe, total final energy consumption and domestic material consumption have increased by more than $7 \%$ and $8 \%$, respectively, during the period 1990-2008 (Eurostat 2013a, b). Life cycle assessment
(LCA) has been broadly used to systematically study the environmental consequences of products and technologies through a process-based accounting of material and energy throughputs. However, functional unit-based LCA models are generally focused on the technology dimension, that is, on specifying the environmental impact per unit of consumption (Heijungs et al. 2009). By using LCA data alone, one thus ignores the level of consumption of the studied product systems. Such disregard has two main implications. First, overall environmental impacts caused by consumption of products by society as a whole are not accounted for, and therefore the magnitude of these impacts is

Address correspondence to: David Font Vivanco, Institute of Environmental Sciences (CML), Leiden University, P.O. Box 9518, 2300 RA Leiden, the Netherlands. Email: Font@cml.leidenuniv.nl Web: http://www.cml.leiden.edu/ 
ignored. Second, differences between levels of consumption of different product systems in comparative LCAs are disregarded because of the commonly accepted "constant demand assumption," that is, the assumption that a change from a product system A to a product system B delivering the same functional unit will not entail a change on level of consumption (Girod et al. 2011). These considerations have implications for sustainable consumption policies, given the use of LCA as one of the tools for decision and policy making (Guinée et al. 2010).

The appraisal of efficient sustainable consumption policies thus requires the assessment of (1) the environmental consequences of products and technologies at higher levels of analysis as well as (2) the relationship between demand and technological characteristics. Regarding the former, several approaches have been developed to scale up LCA data. For instance, by combining input-output analysis (IOA) and macroeconomic models (e.g., partial and general equilibrium models) with LCA data in the form of input-output (I/O)-LCA, environmentally extended IOA (EIOA) or hybrid LCA (Suh 2009; Finnveden et al. 2009; Suh and Nakamura 2007), among others—also, by means of scenario-based LCA (Fukushima and Hirao 2002) and consequential LCA (Zamagni et al. 2012), as well as other possible approaches (Jeswani et al. 2010). While offering a wide range of analytical possibilities for meso- and macromodeling, some of these approaches present different setbacks. For instance, they require data that may not be readily available or in an adequate format (e.g., I/O tables [IOTs] or social accounting matrices) or rely on complex, multilayer modeling (e.g. computable general equilibrium models). Moreover, some of these approaches, for example, those based on IOA, are constrained by the resolution of the tables they feed from and therefore cannot match the relatively higher technological explicitness that micro-level models, such as LCA, can offer (Jaccard et al. 2003). With respect to the relationship between demand and the technological characteristics of products, these can induce changes in demand as a result of the so-called rebound effects (Berkhout et al. 2000; Dimitropoulos and Sorrell 2006; Greening et al. 2000; Khazzoom 1980; Sorrell 2007), which can be briefly defined as the behavioral or other systemic responses to changes in the production or consumption factors (Sorrell 2007; Weidema 2008). Rebound effects are seldom appraised in LCA studies, even though many have argued for the potential advantages of shifting from the "constant demand" paradigm (Ekvall 2000; Goedkoop et al. 1999; Zamagni et al. 2008; Heijungs et al. 2009; Hertwich 2005) and their relevance in the final results (Girod et al. 2011; Weidema 2008).

The overall level of consumption of products can be determined in terms of consumption activity and population growth, similarly to the concepts from the IPAT equation introduced by Ehrlich and Holdren $(1971,1972)$. In this sense, a number of attempts have been made to develop a methodological framework that integrates these two dimensions into LCA (Heijungs et al. 2009; Machida 2011; Hertwich, 2005), which we label as the IPAT-LCA model. Such a method could offer a simple, lowdata-intensive way to scale up LCA data to higher levels of analysis while keeping a high level of technology detail. However, the potentials and limits of this approach are currently not fully explored. The structure of such a framework would also allow for meaningful analyses on the contribution of each dimension (technology, consumption activity, and population growth) to environmental impacts, for instance, by means of decomposition analysis. Assessments, including structural changes in the technosphere, can be carried out using structural decomposition analysis (SDA), whereas simpler analysis at the sector level can be performed using index decomposition analysis (IDA) (Hoekstra and van den Bergh 2003). Moreover, because technological changes can induce changes in consumption activity resulting from rebound effects, it is theoretically possible to study the contribution of such changes both in terms of technology and consumption activity.

This article has two main aims:

- To develop a general analytical framework for the IPATLCA model

- To combine this framework with decomposition analysis to empirically estimate the contribution of the different factors of the IPAT-LCA model behind changes in environmental indicators for the case of diesel passenger cars, focusing on the specific contribution of diesel engines

\section{Methodology and Data}

\section{The IPAT/LCA Model}

One of the first attempts to decompose changes in environmental loads in terms of contributing factors is the IPAT equation, introduced by Ehrlich and Holdren (1971, 1972). Ehrlich and Holdren first introduced the IPAT equation as such by reformulating and mathematically developing an equation that appeared on Barry Commoner's book, "The Closing Circle" (Commoner 1971). In its basic form, the mathematical formulation of the IPAT equation is the following, as shown in equation (1):

$$
i=p \cdot a \cdot t
$$

where $i$ is the level of pollution, $p$ the size of the population, $a$ the affluence, measured as the gross domestic product (GDP) per capita, and $t$ the technology, measured as the pollution per unit of GDP. The equation takes on the characteristics of an accounting identity, because population and GDP on the right side of the equation always cancel out and therefore the fact that pollution equals pollution always holds true (Chertow 2000). Moreover, the identity assumes linearity of the explanatory variables, although more sophisticated forms have been devised using the IPAT concept as a starting point (Chertow 2000). As a consequence, as Kapur and Graedel $(2004,11)$ suggest, it "should be viewed as conceptual rather than mathematically rigorous," adding also that "it can be used to suggest goals for technology and society."

Other authors have criticized the fact that the IPAT equation has been traditionally used to calculate the technology factor by treating it as the residual of the accounting 
identity, because the other factors are more accessible to researchers (Chertow 2000). For example, Dietz and Rosa (1994, 287) argue that, if technology is treated as a residual, then it "captures not just technology in the narrow sense, but everything else not included in the model," for example, "attitudes, values, institutional arrangements etc. of the population." From another angle, Heijungs and colleagues (2009) argue that the pollution and technology variables used in the IPAT equation are not simple numbers, but multidimensional concepts, and propose the following formulation shown in equation (2):

$$
i=T \times A \times p
$$

where $i$ is a vector of $n$ types of environmental loads, T (technology) is a matrix of $n$ rows of environmental impact types and $m$ columns of economic product types, A (consumption activity) is a matrix of $m$ rows of economic product types and $l$ columns of consumer types, and $p$ is a vector of $l$ types of consumers. ${ }^{1}$ A computational example of this formulation can be found in Heijungs and colleagues (2009). It should be noted that, in this formulation, the term consumption activity has replaced the term affluence from the IPAT equation. This is because consumption activity, understood as the consumption of products by consumers, represents more explicitly the demand for products, whereas affluence is but a driver of demand. This formulation presents a high resemblance with the mathematical formulation of life cycle inventory (LCI), which is one of the stages of LCA, and which aim is to account for the input and output flows from, and to nature for, a product system during all its life cycle (ISO 2006). The mathematical formulation of LCI has been described as follows in equation (3) (Heijungs and Suh 2002):

$$
i=T \times f
$$

with equation (4):

$$
T=T_{\_} e n v \times T_{\_} t e c h^{-1}
$$

where $i$ is a vector of $n$ types of environmental interventions, $T$ is the intensity matrix, consisting of $n$ rows of environmental interventions and $m$ columns of product types, $f$ is the final demand vector of $m$ types of products, $T_{-}$env is the intervention matrix, consisting of $n$ rows of environmental interventions and $m$ columns of unit processes, and $T_{-} t e \mathrm{ch}^{-1}$ is the inverse of the technology matrix, consisting of $m$ rows of unit processes and $m$ columns of product types. However, functional unit-based LCA is usually "geared along the target of specifying the environmental impact per unit of consumption," being the latter a given "commodity basket that is specified by the functional unit," thus ignoring demand (Heijungs et al. 2009, 30). Therefore, by incorporating the population and consumption activity directions from the IPAT equation, the external demand of the product system is defined by the output consumption of the socioeconomic system, rather than by an a priori specified demand. Conveniently, the final demand vector in LCI can be described as a product of population and consumption activity (Heijungs et al. 2009) and thus equation (3) can be ex- pressed identically to equation (2). With this formulation, the similarities between the IPAT equation and the LCI become more evident, the main differences being the multidimensionality characteristic in LCI, resulting from the matrix and vector treatment of the explanatory variables (see table 1) as well as the splitting of T into T_env and T_tech.

By using this approach, some shortcomings from both the IPAT and LCA methodologies can be overcome. On one hand, by using LCA, the technology factor need no longer to be treated as the residual of the accounting identity, but an exogenous variable calculated with physically measured data (Machida 2011), covering also impacts through the entire life cycle of products and product systems. Also, by exogenously computing the technology factor, non-technology-related effects, such as structural changes in the economy not related to technological changes (e.g., new market equilibriums resulting from material scarcity), can be differentiated from the purely technological effect. Moreover, by considering technology and consumption activity as multidimensional concepts, multiple environmental pressures, economic activities, and consumer types can be considered, offering a more comprehensive approach into the contributing factors leading to environmental loads. Further, with the help of the consumption activity and population growth variables from the IPAT equation, the environmental profile of a product or product system can be scaled up to the socioeconomic system level. Because data on consumption activity are based on historical interactions, it is behaviorally realistic (Cheuk Wai Mau 2005) and is thus able to capture different phenomena taking place at the macro level related to consumer and market behavior, such as rebound effects.

\section{The IPATILCA Approach for the Case Study}

Following the structure and nomenclature described in table 1, the different categories and types of variables considered are presented in table 2 . The justification for choosing the latter is discussed in the system definition and sources of data section.

As described in table 2, only one type of product and consumer are considered, and because of this, both the consumption activity (referred to as travel demand in the case study) and population factors will adopt a scalar magnitude. In contrast, the technology factor takes the form of a $2 \times 2$ coordinates matrix and the environmental intervention factor the form of a 2 coordinates vector.

\section{Decomposition Analysis}

The contribution of the driving mechanisms behind a certain environmental load can be studied in a more comprehensive way if approached in terms of change. By doing so, one studies how the changes in the driving mechanisms contribute to the change in an environmental load during a time period. This can be particularly relevant when studying the environmental repercussions of innovation, because this pivots around 
Table I Analogies between the formulation of the IPAT equation and life cycle inventory (LCl). Based on Machida (20 I I)

\begin{tabular}{|c|c|c|c|c|}
\hline Variable & IPAT equation & Magnitude & LCI & Magnitude \\
\hline Formulation & $i=p \cdot a \cdot t$ & & $\begin{array}{l}i=T \times f \\
i=T \times A \times p\end{array}$ & \\
\hline Impact & $i=i m p a c t$ & Scalar & $\begin{array}{l}i=\left[\begin{array}{c}l_{1} \\
\vdots \\
i_{n}\end{array}\right] \\
i_{n}=\text { type of environmental intervention } n\end{array}$ & Vector \\
\hline Technology & $t=\frac{i m p a c t}{G D P}$ & Scalar & 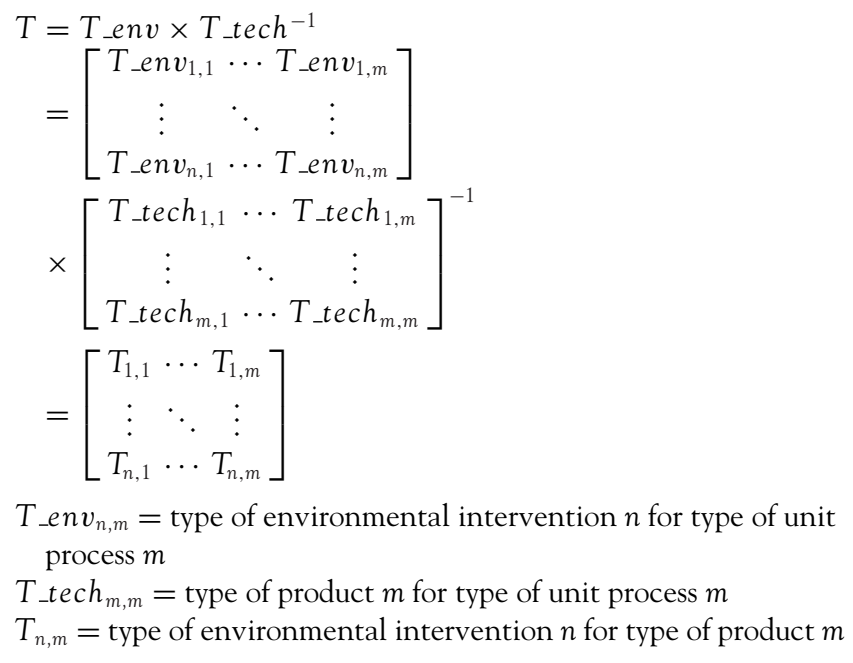 & Matrix \\
\hline $\begin{array}{l}\text { Affluence (IPAT) } \\
\text { Consumption } \\
\text { activity (LCI) }\end{array}$ & $a=\frac{G D P}{\text { Population }}$ & Scalar & $\begin{array}{l}A=\left[\begin{array}{ccc}A_{1,1} & \cdots & A_{1, l} \\
\vdots & \ddots & \vdots \\
A_{m, 1} & \cdots & A_{m, l}\end{array}\right] \\
A_{m, l}=\text { type of product } m \text { for type of consumer } l\end{array}$ & Matrix \\
\hline Population & $p=$ Population & Scalar & $\begin{array}{l}p=\left[\begin{array}{c}P_{1} \\
\vdots \\
p_{l}\end{array}\right] \\
P_{l}=\text { population of type of consumer } l\end{array}$ & Vector \\
\hline
\end{tabular}

the concept of change. To fulfill this need, various decomposition methods have been designed, from which the SDA and the IDA stand out as the most commonly used by researchers. The main difference between these two techniques is that SDA is based on input-output (I/O) data, whereas IDA uses aggregate data at the sector level (Hoekstra and van den Bergh 2003). The proposed IPAT-LCA model is suitable for both SDA and IDA approaches because of its matrix formulation. Thus, structural changes on a certain dimension can be studied if the matrix form is maintained, whereas simpler analyses can be carried out by means of IDA if the rows and/or columns are collapsed into single values (e.g., total carbon dioxide $\left[\mathrm{CO}_{2}\right]$ emissions from all processes and economic sectors studied). We have chosen IDA mainly because of two reasons. First, sectorial data from the diesel passenger cars sector alone have been used for the case study, and thus it is not possible to capture structural changes among multiple economic sectors. Second, it is not possible to assess structural changes among the unit processes comprising the technology dimension because, as argued later on in the next section, complete and consistent LCI data for at least two time points are currently not available. Because of this, a second set of LCI data have been obtained by modeling a single (yet the most contributing) process, which entails that the values of the rest of the processes would remain the same and therefore that no structural changes would be observed. As a result of using IDA, the matrices and vectors characterizing the dimensions described in table 1 have been collapsed by simple aggregation into the single values described in table 2 .

Within IDA, Ang (2004, pp. 1137-1138) concluded the analysis of different methods by recommending the multiplicative and additive logarithmic mean divisia index (LMDI) methods "due to their theoretical foundation, adaptability, 
Table 2 Categories and types of variables considered for the case study

\begin{tabular}{ll}
\hline Category & $\begin{array}{c}\text { Number (in brackets) and } \\
\text { types of variables considered }\end{array}$ \\
\hline $\begin{array}{c}\text { Environmental } \\
\text { intervention }(i)\end{array}$ & (2) $\mathrm{CO}_{2}$ and $\mathrm{NO}_{\mathrm{x}}$ air emissions \\
$\begin{array}{c}\text { Set of unit } \\
\text { processes }\end{array}$ & $\begin{array}{c}\text { (2) Process tree related to the use of average } \\
\text { diesel and gasoline passenger cars from } \\
\text { the European fleet for the year 2005. }\end{array}$ \\
Product type & $\begin{array}{l}\text { (1) vkm } \\
\text { Consumer type }\end{array}$ \\
\hline
\end{tabular}

Note: $\mathrm{CO}_{2}=$ carbon dioxide; $\mathrm{NO}_{\mathrm{x}}=$ nitrogen oxides; $\mathrm{vkm}=$ vehicle kilometers driven.

ease of use and result interpretation, and some other desirable properties in the context of decomposition analysis," for example, the inexistence of residuals (Ang et al. 1998). LMDI methods have been used to analyze the contributing factors of changes in environmental indicators in several studies, mostly focused on $\mathrm{CO}_{2}$ emissions (e.g., Hatzigeorgiou et al. 2008; Liu et al. 2007; Löfgren and Muller 2008; Timilsina and Shrestha 2009; Wang et al. 2011).

The mathematical structure of the IPAT-LCA model (see equation (5), in the form of an accounting identity, permits one to analyze the results by means of decomposition techniques without further calculations. It is then possible to analyze the contribution of changes in the different explanatory variables (technology, consumption activity, and population) in which an aggregated variable (environmental load) can be decomposed. Therefore, the total change in the environmental load between a base year 0 and a target year $t$ can be decomposed by additive decomposition ${ }^{2}$ in three different effects as follows:

$$
(\Delta i)_{t o t}=i^{t}-i^{0}=(\Delta i)_{T}+(\Delta i)_{A}+(\Delta i)_{p}
$$

This general formula can be used both to analyze changes during a multiyear time period or on a yearly basis. Additionally, it must be noted that, as explained in the previous section, for the case study, both population and consumption activity factors adopt a scalar magnitude, whereas the technology factor adopts a matrix magnitude and the environmental intervention factor adopts a vector magnitude. However, as stated before, IDA methods are based on aggregated indexes, that is, scalar values. For this reason, analysis should be performed using single values for both the technology and environmental intervention factors. This has been carried out by choosing a single value regarding the environmental intervention (e.g. $\mathrm{CO}_{2}$ emissions) and a single value with respect to the specified environmental intervention for a set of unit processes regarding the technology factor (e.g., $\mathrm{CO}_{2}$ emissions per vehicle kilometer [vkm] from average diesel passenger cars) for each desired analysis.
According to the LMDI approach described by Ang and Liu (2007), the effect of the explanatory variables can be then calculated as follows with equation (6):

$$
\begin{aligned}
& (\Delta i)_{T}=\frac{i^{t}-i^{0}}{\ln i^{t}-\ln i^{0}} \ln \left(\frac{T^{t}}{T^{0}}\right) \\
& (\Delta i)_{A}=\frac{i^{t}-i^{0}}{\ln i^{t}-\ln i^{0}} \ln \left(\frac{A^{t}}{A^{0}}\right) \\
& (\Delta i)_{p}=\frac{i^{t}-i^{0}}{\ln i^{t}-\ln i^{0}} \ln \left(\frac{p^{t}}{p^{0}}\right)
\end{aligned}
$$

Each of the explanatory variables of the IPAT-LCA model can be further decomposed in additional contributing effects. For example, it is possible to decompose the consumption activity factor in various effects, such as different types of rebound effects. Among these, the direct price rebound effect has been the most studied because of the systemic methodological frameworks available as well as the relatively high availability of econometric tools and the ease of obtaining data on moneyrelated social behavior. Direct price rebound effects can be described as the changes in the demand of a product as a consequence of the allocation of the liberated or bound money from a change in the effective price induced by an improvement option that has been introduced on the same product (Dimitropoulos and Sorrell 2006; Weidema 2008). Both the methodology to further decompose the described explanatory variables and calculate the direct price rebound effect are described in S1 in the supporting information available on the Journal's website.

\section{System Definition and Sources of Data}

This section illustrates the proposed approach with a case study on diesel engines in passenger cars in Europe in order to study the effect of the explanatory variables (technology, travel demand, and population) on different environmental impact indicators during a certain time period. Moreover, the case study will try to calculate the aggregate effect of innovation on both the technology and travel demand factors. For this purpose, the innovation (diesel engines in passenger cars) will be compared to a relevant alternative (gasoline engines in passenger cars) in order to calculate its relative performance. Also, the direct price rebound effect associated with the fuel savings from diesel engines will be calculated.

As explained before in the IPAT-LCA model section, there is no need to specify a functional unit for the system (e.g., kilometers driven during the lifetime of a car), because, in the IPAT-LCA model, the external demand of the product system is exogenously given by the output consumption of the socioeconomic system, namely, consumption activity (travel demand per capita for passenger cars) and population size. Environmental loads per economic output (technology factor) will be analyzed through LCA on a cradle-to-grave basis (ISO 2006). The system will also be defined by spatial and temporal boundaries, which will correspond to the European Union (EU)-27 states' territory and the period 1990-2005, respectively. 
In order to account for the different explanatory variables, different kinds of data are needed. For the technology factor, life cycle data on European average diesel and gasoline passenger cars fleet have been obtained from the Swiss LCA database, ecoinvent 2.2 (ecoinvent Center 2010; Frischknecht et al. 2005). The set of unit processes data for diesel and gasoline passenger cars contains a total amount of 1,296 environmental extensions (emissions, natural resources extraction, and land use), from which $\mathrm{CO}_{2}$ and nitrogen oxides $\left(\mathrm{NO}_{\mathrm{x}}\right)$ air emissions have been selected because of their widely acknowledged relevance in transport (EEA 2009). Apart from their relevance, these substances have been chosen because of the differing trends regarding the relative emissions according to most of the studies found in the literature $\left(\mathrm{CO}_{2}\right.$ emissions from diesel engines would be relatively lower, compared to gasoline engines, and $\mathrm{NO}_{\mathrm{x}}$ emissions present the opposite case), which offers an opportunity to assess the influence of different technological pathways on both the other explanatory variables and the total emissions. However, two major challenges arise when studying time series by means of LCA data: First, systematic compilation of information for most processes for LCA databases started in the early 2000s, and therefore data constraints are significant for the years before. In the case of passenger cars in the ecoinvent database, which is one of the inceptive, most complete LCA databases available, the first year for which information on average fleet passenger cars in Europe is available corresponds to 2005 (which is the last year of the studied time period). Second, data sets for every process are not produced on a yearly basis. Therefore, because one of the primary objectives of the present study is to analyse technological change over time, information from this database has been modelled to reflect yearly evolution, thus building a temporally dynamic LCA model (for similar exercises, see Fukushima and Hirao [2002] or Pehnt [2006]). However, only the emissions from the operation stage have been modeled as a result of data availability, and thus other emissions from up- and downstream processes have been assumed to remain constant over time. ${ }^{3}$ Concretely, $\mathrm{CO}_{2}$ emissions have been modeled through time according to data on the car fleet fuel consumption from monitoring reports published by the European Commission and $\mathrm{NO}_{\mathrm{x}}$ emissions according to emission factors used in the model COPERT 4. A detailed explanation of the methodology followed can be found in $\mathrm{S} 2$ in the supporting information on the Web.

The travel demand factor will be determined by both the stock of diesel and gasoline passenger cars in use and the travel demand for passenger cars. The former will be calculated using the FLEETS database (Ntziachristos et al. 2008). For the calculation of the travel demand, the ALTER-MOTIVE database has been used (Ajanovic 2011). In order to account for the relative travel demand for diesel and gasoline engines, data from the FLEETS database have been used, according to which diesel passenger cars are driven $66.89 \% \mathrm{vkm}$ more in the EU-27. However, this information is only available for the year 2005, the reason for which this value has been used for the entire time series. In so doing, our analysis overlooks yearly differences in usage patterns between diesel and gasoline cars during the studied time period.

In order to account for the direct price rebound effect from fuel efficiency improvements, a long-term fuel price elasticity of vkm of -0.26 has been used, which corresponds to an average value derived from a survey on various studies conducted for the EU (de Jong and Gunn 2001), as well as historic data on diesel and gasoline retail prices obtained from the European Federation for Transport and Environment (2011). ${ }^{4}$

In addition, the population size for all the European member states during the studied time series has been accounted for according to the Eurostat statistical database (Eurostat 2013c). Last, all the information needed for the calculations is summarized in S4 in the supporting information on the Web.

\section{Results and Discussion}

Figures 1 and 2 present the results of the decomposition analysis of the life cycle emissions of $\mathrm{CO}_{2}$ and $\mathrm{NO}_{\mathrm{x}}$ from diesel passenger cars in Europe. The results describe a general trend for both emissions during the studied time period in which travel demand and population size effects present a positive contribution, therefore driving emissions up, and technology has an opposite effect. However, travel demand is the effect that has contributed the most during the period 1990-2005 both for $\mathrm{CO}_{2}$ and $\mathrm{NO}_{\mathrm{x}}$ emissions, with a relative change of $112 \%$ and $178 \%$, respectively, and has thus provoked a constant overall increase in both emissions. The relative change in the contribution of population growth would be of $4 \%$ and $6 \%$, respectively, and of $-16 \%$ and $-84 \%$, respectively, from technology. This tendency is consistent with similar studies, such as those performed by the IEA (2007) or the EEA (2011), which point out the increased consumption activity as the most important factor underlying the evolution of emissions and energy use in transport. It is also noteworthy to point out the fact that, whereas the general trend may offer valuable general insights, yearly changes are more prone to be influenced by quality of the data. For instance, data on travel demand for the year 2005 might be underestimated as a result of reporting issues, because the break in the trend is not entirely supported by empirical evidence. According to the methodology previously exposed, these data have an effect on both the marginal changes in travel demand and the technology factor, which thus describe a discontinuity in the trend followed in the previous years.

By analyzing each effect in detail, the following qualified conclusions can be drawn from the obtained results. First, the increasing diffusion of diesel engines is the main cause underlying the constant increase for travel demand for diesel cars, because relative $\mathrm{vkm}$ from diesel cars with respect to their gasoline counterparts has been assumed to remain constant and travel demand for passenger cars shows a certain stagnation during the studied time period (see S4 in the supporting information on the Web). Second, in the case of $\mathrm{CO}_{2}$ emissions, the decreased emissions as a consequence of technology are the outcome of constant improvements in fuel economy alone, because 


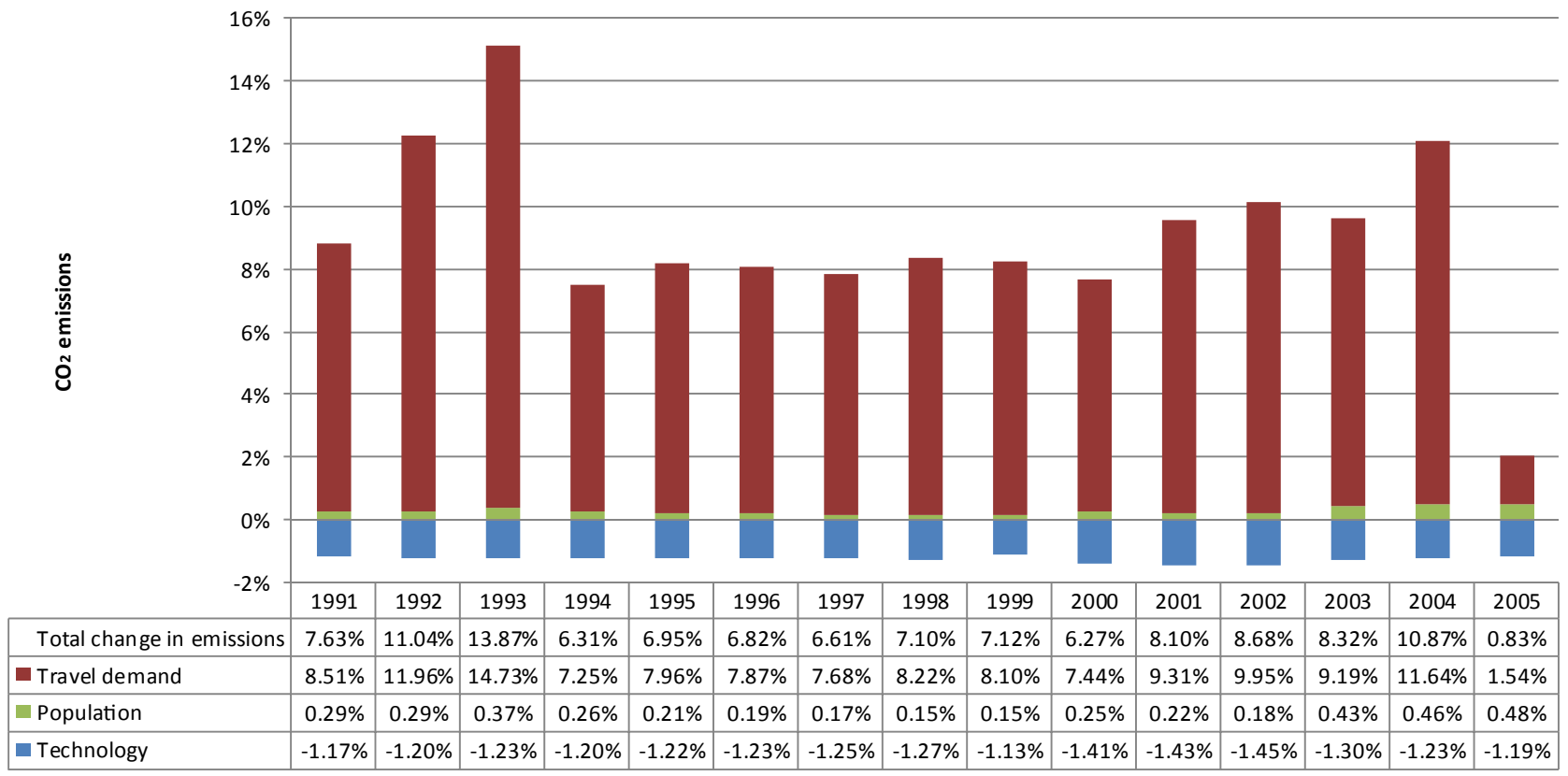

Figure I Total annual change and contribution of the explanatory variables (in percentage) to total annual change in life cycle $\mathrm{CO}_{2}$ emissions from the diesel passenger car fleet in the $\mathrm{EU}-27 . \mathrm{CO}_{2}=$ carbon dioxide; $\mathrm{EU}=$ European Union.

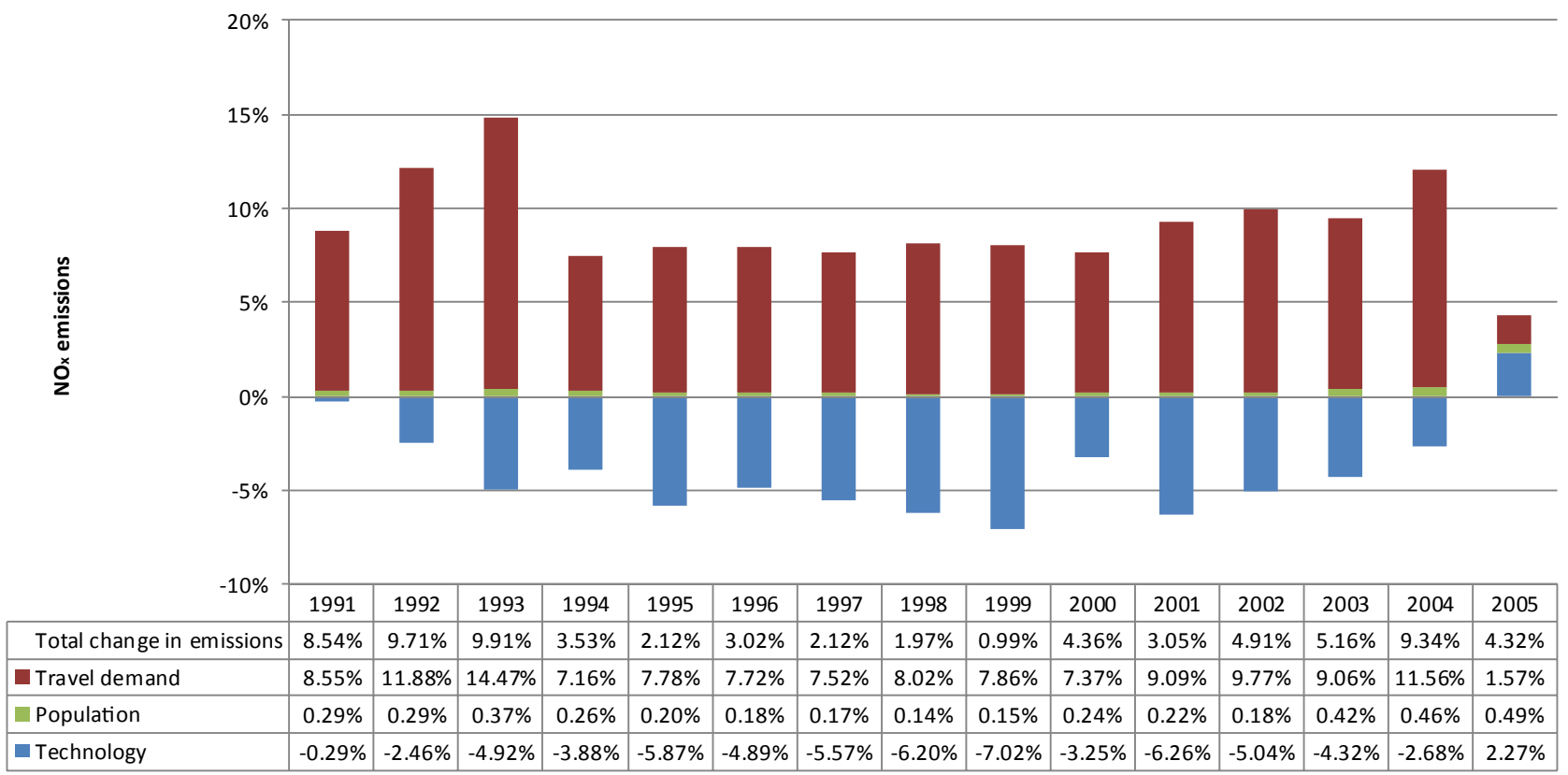

Figure 2 Total annual change and contribution of the explanatory variables (in percentage) to total annual change in life cycle $\mathrm{NO}_{x}$ emissions from the diesel passenger car fleet in the $\mathrm{EU}-27 . \mathrm{NO}_{x}=$ nitrogen oxides; $\mathrm{EU}=$ European Union.

relative emissions (emissions per unit of fuel) have been assumed to remain constant as a result of data availability. Regarding $\mathrm{NO}_{\mathrm{x}}$ emissions, the improvement in technology is mainly the outcome of the progressive diffusion of cars with higher emission standards on the European car fleet, which fostered the introduction of more-efficient technologies in the automotive catalysts (Kaspar et al. 2003). Thus, the relative higher contribution of technology in driving emissions down in the case of $\mathrm{NO}_{\mathrm{x}}$ implies that technological changes regarding efficiency of catalysts have had a bigger impact than those on fuel economy for $\mathrm{CO}_{2}$ emissions. Last, population is not an important effect for the EU-27 as a whole; it is more important for some countries than for others, given that population growth has been uneven in Europe.

Table 3 presents the results of the decomposition analysis for $\mathrm{CO}_{2}$ and $\mathrm{NO}_{\mathrm{x}}$ emissions in absolute terms. Also, the 
RESEARCH AND ANALYSIS

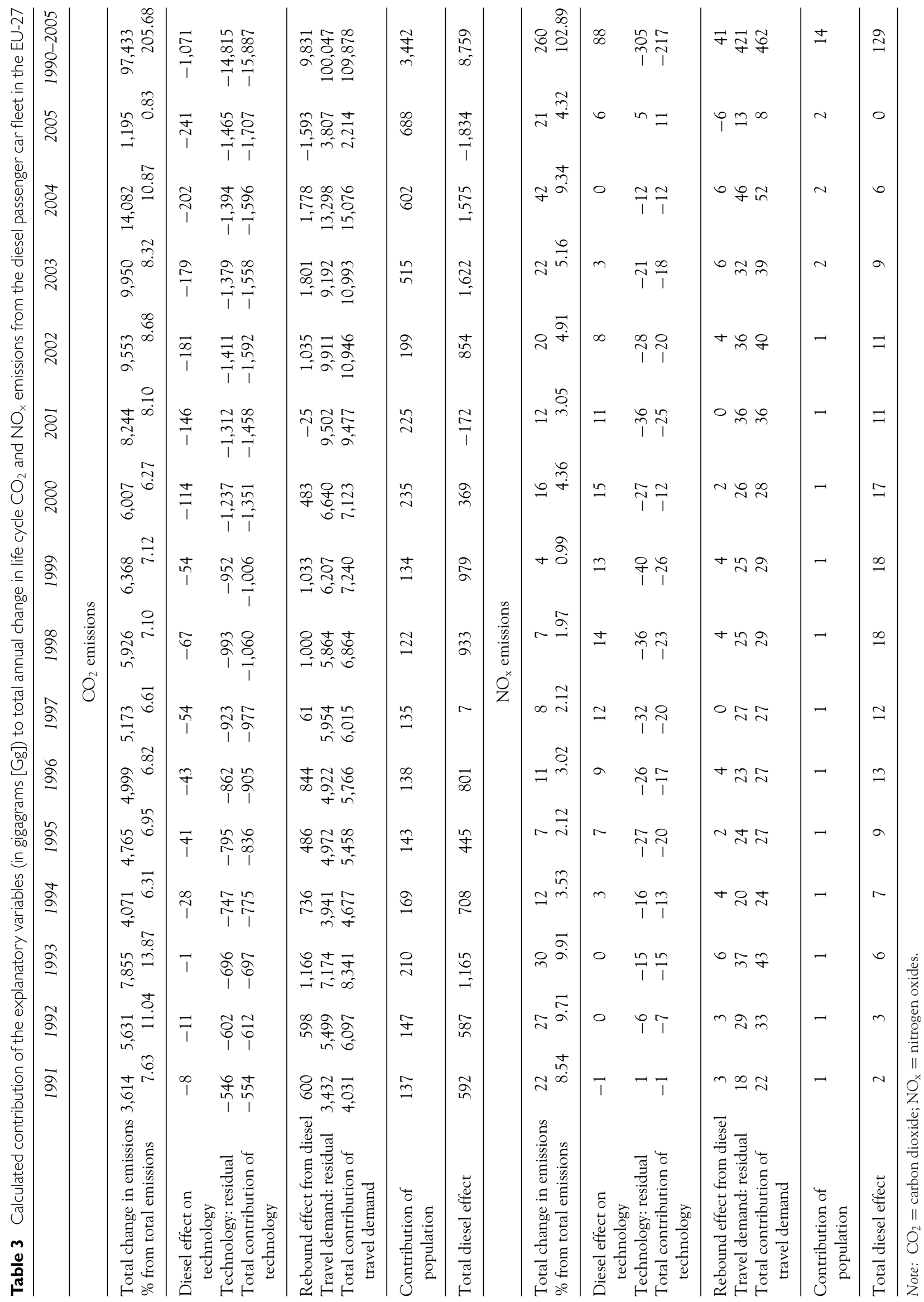




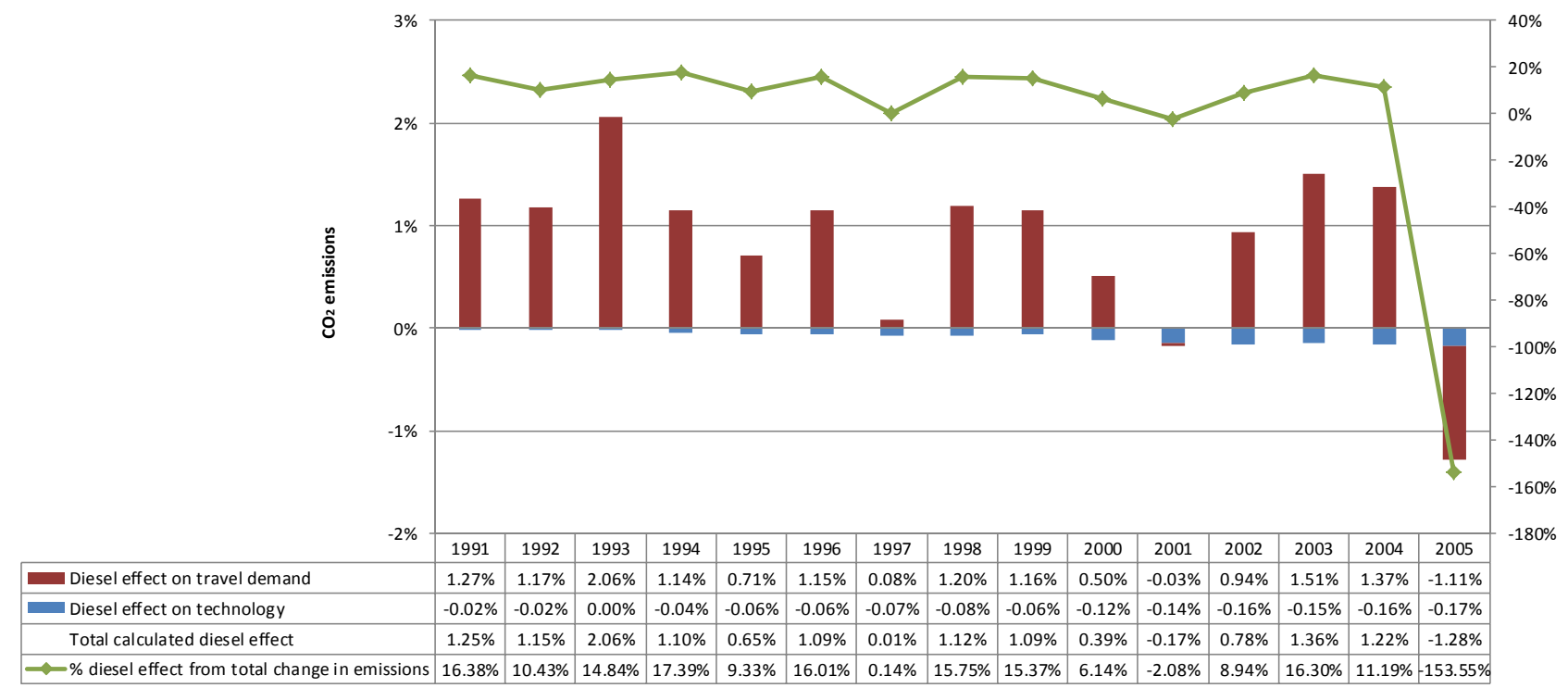

Figure 3 Calculated contribution of the diesel effect on travel demand and technology (in percentage) to total annual change in life cycle $\mathrm{CO}_{2}$ emissions from the diesel passenger car fleet in the EU-27. $\mathrm{CO}_{2}=$ carbon dioxide; $\mathrm{EU}=$ European Union.

explanatory variables, technology and travel demand, have been further decomposed to calculate the direct contribution of diesel engines (see S1 in the supporting information on the Web). According to our approach, the calculated effect of diesel engines on technology corresponds to the emissions that can be attributed to the innovation, that is, the relative emissions, compared to the relevant alternative (gasoline engines) on a life cycle basis (see the system definition and sources of data section). This approach assumes that the technological characteristics of engines alone are responsible for the relative differences in $\mathrm{CO}_{2}$ and $\mathrm{NO}_{\mathrm{x}}$ emissions from diesel and gasoline passenger cars. The remaining contribution (residual) can be related to transversal improvements in internal combustion engines and other features of the cars (e.g., aerodynamics). The calculated effect of diesel engines on travel demand has been assumed to correspond to the direct price rebound effect previously introduced (see S1 in the supporting information on the Web). We therefore assume that the change in travel demand that stems from the technological characteristics of diesel engines corresponds to the direct price rebound effect alone, leaving other self-selection effects ${ }^{5}$ (Schipper and Fulton 2009) out. Such an assumption also leaves out other effects that can be linked as well to the technological characteristics of the innovation, such as additional spending on extra features (Girod and de Haan 2010; Zamagni et al. 2008; Schipper and Fulton 2009), indirect and structural effects (Greening et al. 2000), or non-price rebound effects (Santarius 2012; Weidema 2008), which have not been accounted for because it falls outside the scope of this research. Such effects, as well as the rest of the factors contributing to determine the level of consumption, have been captured in the form of a residual. Last, both contributions have been aggregated to determine the total effect of diesel engines on life cycle emissions. Moreover, figures 3 and 4 present the contribution (in percentage) of the calculated effects on both travel demand and technology, as well as the contribution of the combined effects on the total change in emissions.

The results describe a large contribution of diesel engines to the increase of both total life cycle $\mathrm{CO}_{2}$ and $\mathrm{NO}_{\mathrm{x}}$ emissions from diesel passenger cars, contributing to almost $9 \%$ and $50 \%$, respectively, to total emissions during the studied time period. The contribution of technology and travel demand is, however, asymmetrical between $\mathrm{CO}_{2}$ and $\mathrm{NO}_{\mathrm{x}}$ emissions. In the case of $\mathrm{CO}_{2}$ emissions, the results indicate that the direct price rebound effect induced by diesel engines on travel demand would have offset emission reductions from the effect of diesel engines on technology by almost a factor of ten. Thus, emission reductions on the technology side would have been not only compensated by the rebound effect, but also largely increased. Regarding $\mathrm{NO}_{\mathrm{x}}$ emissions, both the effect of diesel on technology and travel demand have been overall positive, with the calculated effect on technology being higher by a factor of two. These disparities are mainly explained by the differences between the emissions from diesel and gasoline cars, which affect the magnitude and trend of the effect on technology.

With regard to the percentage of the calculated diesel effect from the total change in emissions, it presents a more or less steady evolution in the case of $\mathrm{CO}_{2}$ emissions, except for the year 2005, in which a notable increase in the price of diesel fuel (European Federation for Transport and Environment 2011) reduced the magnitude of the rebound effect and therefore the calculated effect on travel demand, which became negative for this year. Regarding $\mathrm{NO}_{\mathrm{x}}$ emissions, an inverse $\mathrm{V}$-shaped evolution can be observed, with the maximum on the year 1999. This evolution was mainly driven by changes in the calculated effect 


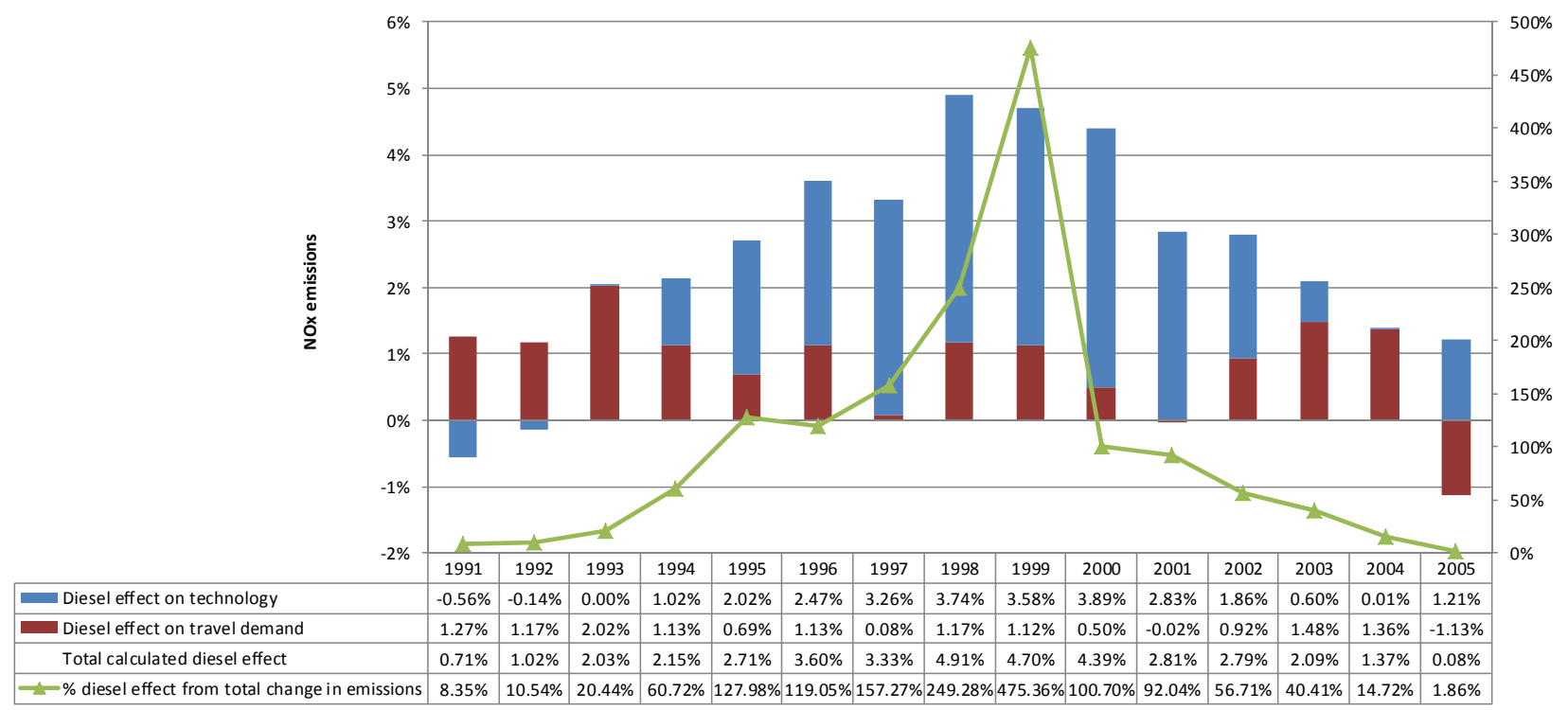

Figure 4 Calculated contribution of the diesel effect on travel demand and technology (in percentage) to total annual change in life cycle $\mathrm{NO} \times$ emissions from the diesel passenger car fleet in the EU-27. $\mathrm{NO}_{\times}=$nitrogen oxides; $\mathrm{EU}=$ European Union.

on technology, which means that technological improvements on diesel cars, mainly three-way catalysts, diffused relatively less rapidly during the period 1990-1999.

\section{Conclusions}

In this article, the IPAT-LCA model has been used as a tool for scaling up detailed environmental profiles of products by considering aspects of demand at the macro level. Several positive outcomes can be derived by following this approach, from which we highlight the following three. First, the magnitude of the impacts of products at the macro level can be accounted for while maintaining a high technological explicitness. Second, the changes in production and consumption induced by technological characteristics, that is, rebound effects, can be captured and assessed. Third, by using aspects of demand at the macro level, ex-post analyses are considered to be "behaviorally realistic" by incorporating both consumer behavior and market mechanisms. Because of this, we consider this approach to be more comprehensive than using functional unit-based LCA data alone for macro-level assessments, for instance, with respect to strategic sustainability choices regarding the large-scale implementation of innovative products and technologies.

The strengths of the IPAT-LCA model present, at the same time, certain downsides that limit the soundness of the approach. For instance, the fact that demand data at the macro level are combined with technology information from process data at the micro level can lead to inconsistencies. This is because process data are usually limited to a number of processes for which information is available and/or are considered to be representative, whereas, ideally, it should encompass all processes involved in consumption at the macro level. The presented case study illustrates this point: As the meta-data shows, some local processes (e.g., related to the road infrastructure or vehicle disposal) have been used to represent European conditions for the operation of passenger cars, whereas travel demand takes place at the European level. This is undoubtedly a relevant source of uncertainty, as is the case of other macroassessment methods that follow similar approaches (e.g., IO-LCA or EIOA methods) (Suh and Huppes 2002). However, compared with other macroassessment LCA-based tools, the IPAT-LCA model offers a low data intensive, simple way of scaling up micro-level LCA data to higher levels of analysis, especially those within the sector level (e.g., a particular segment of passenger cars). For multisector or macroeconomic assessments, IO-based tools would be more suitable, because the required information on the structure of the economy is readily available in the form of IOTs. Additionally, it must be stressed that the data input for the IPAT-LCA is generally more specific and thus may not be always readily available (as the case study has brought to attention). The fact that demand (functional unit) can be calculated in units representing the real functional output of products (e.g., vkm driven by diesel passenger cars) presents also an advantage, because no conversions are needed to calculate the LCA results (as it can be the case, e.g., when monetary IOTs are used).

Also, by introducing a temporal resolution to the IPATLCA by means of modeling, its structure permits one to carry out a deeper analysis into the contributing factors by means of decomposition techniques, offering a broader insight into the sources of change. The matrix-based mathematical structure of the IPAT-LCA model allows for assessment of structural changes using SDA as well as simpler analyses using aggregate data by means of IDA. Whereas the present study has illustrated this combination with the use of IDA because of the scope of the analysis and data constraints, the application of SDA can be a potentially suitable approach in those cases in which 
structural changes are both relevant and possible to study. For instance, it is possible to study structural changes within an economy, among the unit processes of a product or among types of consumers. Those potential studies are, however, left for further research. The results of the IDA carried out in the case study would point out the increased consumption activity as the most important factor underlying the increase in both $\mathrm{CO}_{2}$ and $\mathrm{NO}_{\mathrm{x}}$ life cycle emissions from the European diesel passenger car fleet during the period 1990-2005, offsetting technological improvements by a factor of almost ten and two, respectively. Moreover, we have accounted for the specific contribution of this innovation on total $\mathrm{CO}_{2}$ and $\mathrm{NO}_{\mathrm{x}}$ emissions, both in terms of changes in technology and consumption activity, concluding that this has been overall positive (thus driving emissions up)concretely by approximately $9 \%$ and $50 \%$, respectively-with increases in consumption activity as the main driver. According to these results, it can be argued that the introduction of the relatively more energy-efficient diesel engines in passenger cars in Europe entailed an increase in emissions, mainly resulting from the increase in demand caused by the direct price rebound effect.

For reducing vehicle emissions, these results highlight the need to shift sustainable mobility policies from the current technology-oriented mindset to a mix of policies aimed at minimizing demand as well (e.g., through economic instruments [e.g., fuel taxes], urban planning, the promotion of public transport and car sharing, and so on). For instance, the notable increase in fuel prices in the year 2005 would have contributed to considerably reduce the impact of the direct price rebound effect. In order to be effective, this new framework of harmonized policies should consider and understand the dynamics of the drivers of demand, especially aspects related to consumer behavior and market mechanisms, which can lead to undesired rebound effects.

In this sense, LCA-based methods present an appropriate starting point for developing integral frameworks to better inform sustainable mobility policies because of their completeness and systemic approach. Within this perspective, the relative and dynamic nature of innovations can be captured, and innovation policies can be designed accordingly. However, there is still a need for further research to fully understand the entire range of aspects that contribute to changes in technology and demand and which have remained implicit in the form of residuals in our study. To this end, further decomposition of the technology and consumption activity factors is possible. The study of consumer behavior aspects (e.g., the consequences of framing perceptions of new technologies), other price-related rebound effects (e.g., structural or transformational effects), or time, space, or technology availability-related rebound effects are of particular interest. In any case, the exclusion of such aspects is not a defining feature of the IPAT-LCA model as such. LCA-based methods, such as the presented IPAT-LCA model, present great opportunities to further analyze the whole spectrum of social and economic conditions as well as the complete order of consequences that determine the environmental impacts of innovations.

\section{Acknowledgments}

This research has been developed within the framework of the Environmental Macro Indicators of Innovation (EMInInn) project, a collaborative project funded through the EU's Seventh Framework Programme for Research (FP7; grant agreement no. 283002). The authors thank Angelica Mendoza Beltran and Will McDowall for their comments. The comments from four anonymous reviewers are also appreciated.

\section{Notes}

1. A similar matrix-based approach, not directly related to the IPAT equation and slightly more complex, can be found in Hertwich (2005).

2. Multiplicative decomposition is possible as well. However, additive decomposition has been chosen in this study because we consider the results easier to interpret.

3. The operation stage of cars is the stage that contributes the most to emissions. According to MacLean and Lave (1998), these emissions could amount to $76 \%$ to $84 \%$ from total life cycle emissions.

4. Because of the significant impact that this value has on the final results, a sensitivity analysis using both long- and short-run elasticities from different sources can be found in S3 in the supporting information on the Web. In any case, from the results of the sensitivity analysis, it can be determined that the price elasticity value does not alter substantially the main conclusions drawn from the results.

5. For instance, drivers who travel more can be predetermined to use engine technologies with a better fuel efficiency, such as diesel engines. This is, however, irrespective of the fact that they drive diesel cars, because they may have the same driving behavior with an alternative engine technology. According to Schipper and Fulton (2009), self-selection effects would actually be the main contributors to the difference in $\mathrm{vkm}$ driven between diesel and gasoline cars, describing a range from $95 \%$ to $88 \%$ for Europe, depending on the country. The rest could be ascribed to the rebound effect.

6. These process trees contain all the upstream and downstream single unit processes involved in the life cycle of the use of passenger cars.

\section{References}

Ajanovic, A. 2011. Deliverable 2: Database of transport indicators with special focus on alternative fuels and alternative automotive technologies. Deriving effective least-cost policy strategies for alternative automotive concepts and alternative fuels (ALTER-MOTIVE). Vienna: Energy Economics Group.

Ang, B. W. 2004. Decomposition analysis for policymaking in energy: Which is the preferred method? Energy Policy 32(9): 1131-1139.

Ang, B. W. and N. Liu. 2007. Handling zero values in the logarithmic mean Divisia index decomposition approach. Energy Policy 35(1): 238-246.

Ang, B. W., F. Q. Zhang, and K. H. Choi. 1998. Factorizing changes in energy and environmental indicators through decomposition. Energy 23(6), 489-495.

Berkhout, P. H. G., J. C. Muskens, and W. Velthuijsen. 2000. Defining the rebound effect. Energy Policy 28(6-7): 425-432.

Chertow, M. R. 2000. The IPAT equation and its variants. Journal of Industrial Ecology 4(4): 13-29. 
Cheuk Wai Mau, P. 2005. Modeling consumer preferences and technological change: Survey of attitudes to hybrid vehicles. Master's thesis, Simon Fraser University, Burnaby, British Columbia, Canada.

Commoner, B. 1971. The closing circle: Nature, man, and technology. New York: Bantam Books.

de Jong, G. and H. Gunn. 2001. Recent evidence on car cost and time elasticities of travel demand in Europe. Journal of Transport Economics and Policy 35(2): 137-160.

Dietz, T. and E. Rosa. 1994. Rethinking the environmental impacts of population, affluence and technology. Human Ecology Review 1(2): $277-300$.

Dimitropoulos, J. and S. Sorrell. 2006. The rebound effect: Microeconomic definitions, extensions and limitations. Proceedings of the 29th IAEE International Conference, 7-10 June, Potsdam, Germany.

ecoinvent Center. 2010. Ecoinvent data v2.2, 2010. St. Gallen, Switzerland: Swiss Center for Life Cycle Inventories.

EEA (European Environment Agency). 2009. EMEP/EEA air pollutant emission inventory guidebook. Copenhagen: European Environment Agency.

EEA (European Environment Agency). 2011. Greenhouse gas emissions in Europe: A retrospective trend analysis for the period 1990-2008. Copenhagen: European Environment Agency.

Ehrlich, P. R. and J. P. Holdren. 1971. Impact of population growth. Science 171(3977): 1212-1217.

Ehrlich, P. R. and J. P. Holdren. 1972. A bulletin dialogue on the 'closing circle': Critique: One dimensional ecology. Bulletin of the Atomic Scientists 28(5): 16-27.

Ekvall, T. 2000. A market-based approach to allocation at openloop recycling. Resources, Conservation and Recycling 29(1): 91109.

European Federation for Transport and environment. 2011. Fuelling oil demand. What happened to fuel taxation in Europe? Brussels: European Federation for Transport and Environment.

Eurostat 2013a. Final energy consumption, by sector. Luxembourg: Publications Office of the European Union.

Eurostat 2013b. Material flow accounts. Luxembourg: Publications Office of the European Union.

Eurostat 2013c. Population on 1 January. Luxembourg: Publications Office of the European Union.

Finnveden, G., M. Z. Hauschild, T. Ekvall, J. Guinée, R. Heijungs, S. Hellweg, A. Koehler, D. Pennington, and S. Suh. 2009. Recent developments in life cycle assessment. Journal of Environmental Management 91(1): 1-21.

Frischknecht, R., N. Jungbluth, H. J. Althaus, G. Doka, R. Dones, T. Heck, S. Hellweg, et al. 2005. The ecoinvent database: Overview and methodological framework. The International Journal of Life Cycle Assessment 10(1): 3-9.

Fukushima, Y. and M. Hirao. 2002. A structured framework and language for scenario-based life cycle assessment. The International Journal of Life Cycle Assessment 7(6): 317-329.

Girod, B. and P. de Haan. 2010. More or better? A model for changes in household greenhouse gas emissions due to higher income. Journal of Industrial Ecology 14(1): 31-49.

Girod, B., P. Haan, and R. Scholz. 2011. Consumption-as-usual instead of ceteris paribus assumption for demand. The International Journal of Life Cycle Assessment 16(1): 3-11.

Goedkoop, M. 1999. Product service systems, ecological and economic basics. The Netherlands: Ministry of Housing, Spatial Planning and the Environment. Communications Directorate.
Greening, A., D. L. Greene, and C. Difiglio. 2000. Energy efficiency and consumption-The rebound effect-A survey. Energy Policy 28(6-7): 389-401.

Grübler, A. 2003. Technology and global change. Cambridge, UK: Cambridge University Press.

Guinée, J. B., R. Heijungs, G. Huppes, A. Zamagni, P. Masoni, R. Buonamici, T. Ekvall, and T. Rydberg. 2010. Life cycle assessment: Past, present, and future. Environmental Science $\mathcal{E}$ Technology 45(1): 90-96.

Hatzigeorgiou, E., H. Polatidis, and D. Haralambopoulos. 2008. CO2 emissions in Greece for 1990-2002: A decomposition analysis and comparison of results using the Arithmetic Mean Divisia Index and Logarithmic Mean Divisia Index techniques. Energy 33(3): 492-499.

Heijungs, R., G. Huppes, and J. Guinée. 2009. A scientific framework for LCA. Deliverable (D15) of work package 2 (WP2) CALCAS project. Bologna, Italy: National Agency for New Technologies, Energy and Sustainable Economic Development (ENEA).

Heijungs, R. and S. Suh. 2002. The computational structure of life cycle assessment. Dordrecht, the Netherlands: Kluwer Academic Publishers.

Hertwich, E. G. 2005. Consumption and the rebound effect: An industrial ecology perspective. Journal of Industrial Ecology 9(1-2): 85-98.

Hoekstra, R. and J. van den Bergh. 2003. Comparing structural and index decomposition analysis. Energy Economics 25(1): 39-64.

IEA (International Energy Agency). 2007. Energy use in the new millenium. Trends in IEA countries. Paris: OECD/IEA.

ISO (International Organization for Standardization). 2006. ISO 14044: 2006 environmental management-Life cycle assessment-Requirements and guidelines. Geneva: International Organization for Standardization.

Jaccard, M., J. Nyboer, C. Bataille, and B. Sadownik. 2003. Modeling the cost of climate policy: Distinguishing between alternative cost definitions and long-run cost dynamics. Energy Journal 24(1): 49_ 73.

Jeswani, H. K., A. Azapagic, P. Schepelmann, and M. Ritthoff. 2010. Options for broadening and deepening the LCA approaches. Journal of Cleaner Production 18(2): 120-127.

Kapur, A. and T. E. Graedel. 2004. Industrial ecology. Encyclopedia of Energy 3: 373-382.

Kaspar, J., P. Fornasiero, and N. Hickey. 2003. Automotive catalytic converters: Current status and some perspectives. Catalysis Today 77(4): 419-449.

Khazzoom, J. D. 1980. Economic implications of mandated efficiency in standards for household appliances. Energy Journal 1(4): 21-40.

Kemp, R. 1994. Technology and the transition to environmental sustainability: The problem of technological regime shifts. Futures 26(10): 1023-1046.

Liu, L. C., Y. Fan, G. Wu, and Y. M. Wei. 2007. Using LMDI method to analyze the change of China's industrial $\mathrm{CO} 2$ emissions from final fuel use: An empirical analysis. Energy Policy 35(11): 5892-5900.

Löfgren, A. and A. Muller. 2008. The effect of energy efficiency on Swedish carbon dioxide emissions 1993-2004. Working papers in economics no. 311. Göteborg, Sweden: Göteborg University, School of Business, Economics and Law.

Machida, W. 2011. IPAT equation, life cycle inventory analysis and dynamic Leontief model for critical thinking in industrial ecology: Decomposition, attribution and marginal analyses for innovative solutions. Ph.D. thesis, Università Ca' Foscari Venezia, Dorsoduro Venezia, Italy. 
MacLean, H. L. and L. B. Lave. 1998. Peer reviewed: A life-cycle model of an automobile. Environmental Science \&3 Technology 32(13): $322 \mathrm{~A}-330 \mathrm{~A}$.

Ntziachristos, L., G. Mellios, C. Kouridis, T. Papageorgiou, M. Theodosopoulou, Z. Samaras, K. Zierock, et al. 2008. Final report. European database of vehicle stock for the calculation and forecast of pollutant and greenhouse gases emissions with TREMOVE and COPERT. Thessaloniki, Greece: European Commission, Directorate General Environment.

Pehnt, M. 2006. Dynamic life cycle assessment (LCA) of renewable energy technologies. Renewable energy 31(1): 55-71.

Santarius, T. 2012. Green growth unravelled: How rebound effects baffle sustainability targets when the economy keeps growing. Berlin: Heinrich Boell Foundation and Wuppertal Institute for Climate, Environment and Energy.

Schipper, L. and L. Fulton. 2009. Disappointed by diesel? Transportation research record. Journal of the Transportation Research Board 2139(1): 1-10.

Sorrell, S. 2007. The rebound effect: An assessment of the evidence for economy-wide energy savings from improved energy efficiency. Project report. London: UK Energy Research Center.

Suh, S. 2009. Handbook of input-output economics in industrial ecology. Eco-efficiency in industry and science, Vol. 23. Dordrecht, the Netherlands: Springer.

Suh, S. and G. Huppes. 2002. Missing inventory estimation tool using extended input-output analysis. The International Journal of Life Cycle Assessment 7(3): 134-140.

Suh, S. and S. Nakamura. 2007. Five years in the area of input-output and hybrid LCA. The International Journal of Life Cycle Assessment 12(6): 351-352.
Timilsina, G. R. and A. Shrestha. 2009. Factors affecting transport sector CO2 emissions growth in Latin American and Caribbean countries: An LMDI decomposition analysis. International Journal of Energy Research 33(4): 396-414.

Wang, W. W., M. Zhang, and M. Zhou. 2011. Using LMDI method to analyze transport sector CO2 emissions in China. Energy 36(10): 5909-5915.

Weidema, B. 2008. Rebound effects of sustainable production. In Presentation to the "Sustainable Consumption and Production" session of the conferenceBridging the gap: Responding to environmental change-From words to deeds, 14-16 May, Portoro, Slovenia.

Zamagni, P., P. Buttol, R. Porta, R. Buonamici, P. Masoni, J. Guinée, R. Heijungs, et al. 2008. Critical review of the current research needs and limitations related to ISO-LCA practice. Deliverable D7 of work package 5 of the CALCAS project.

Zamagni, A., J. Guinée, R. Heijungs, P. Masoni, and A. Raggi. 2012. Lights and shadows in consequential LCA. The International Journal of Life Cycle Assessment 17(7): 904-918.

\section{About the Authors}

David Font Vivanco is a Ph.D. researcher and Ester van der Voet and Reinout Heijungs are assistant professors and senior researchers, all at the Department of Industrial Ecology of the Institute of Environmental Sciences (CML) at Leiden University in Leiden, the Netherlands. René Kemp is a professorial fellow at UNU-MERIT and at ICIS, Maastricht University, in Maastricht, the Netherlands.

\section{Supporting Information}

Additional Supporting Information may be found in the online version of this article at the publisher's web site:

Supporting Information S1: This supporting information provides an explanation of the methodology for the decomposition of the main explanatory variables and the calculation of the direct price rebound effect.

Supporting Information S2: This supporting information provides an explanation of the methodology for modeling $\mathrm{CO}_{2}$ and $\mathrm{NO}_{\mathrm{x}}$ operation-stage emissions.

Supporting Information S3: This supporting information provides a sensitivity analysis of the main results of the study in terms of price elasticity values.

Supporting Information S4: This supporting information provides a table showing a summary of the data needed for the calculations. 